\title{
REVIEW
}

\section{Biofuels and food security}

\author{
Dmitry S. STREBKOV (凶)
}

All-Russian Research Institute for Electrification of Agriculture (VIESH), 1-st. Veshnyakovsky proezd, 2, Moscow 109456, Russia

\begin{abstract}
The major source of energy comes from fossil fuels. The current situation in the field of fuel and energy is becoming more problematic as world population continues to grow because of the limitation of fossil fuels reserve and its pressure on environment. This review aims to find economic, reliable, renewable and non-polluting energy sources to reduce high energy tariffs in Russian Federation. Biofuel is fuel derived directly from plants, or indirectly from agricultural, commercial, domestic, and/or industrial wastes. Other alternative energy sources including solar energy and electric power generation are also discussed. Over $100 \mathrm{Mt}$ of biomass available for energy purposes is produced every year in Russian. One of the downsides of biomass energy is its potential threatens to food security and forage industries. An innovative approach proved that multicomponent fuel $(80 \%$ diesel oil content for motor and $64 \%$ for in stove fuel) can remarkably reduce the costs. This paper proposed that the most promising energy model for future is based on direct solar energy conversion and transcontinental terawatt power transmission with the use of resonant wave-guide technology.
\end{abstract}

Keywords fossil fuels, biofuels, food security, electric power, solar energy

\section{Introduction}

Energy consumption per head of population in Russia is half that of the USA and Canada, even though Russia is the coldest country in the world. Maximum load on the energy system occurs in the winter season, and fuel consumption for heat and electricity supply to residential and industrial buildings accounts for nearly $65 \%$ of total fuel and energy consumption. To reduce high energy tariffs in the Russian

Received January 20, 2015; accepted March 4, 2015

Correspondence: viesh@dol.ru
Federation (RF), it is necessary to increase the fuel utilization factor through energy generation at highly effective cogeneration plants, to decrease fuel cost and to develop biofuel and low-carbon energy production with the use of renewable energy sources ${ }^{[1-3]}$. Research and development in renewable energy has been stimulated by the well-known requirement of funding energy sources alternative to fossil fuels, to prevent increasing atmospheric $\mathrm{CO}_{2}$. For meeting the above need non-polluting energy sources should be found, which do not have health risks, are economically competitive when compared to oil sources that are easily discovered and exploited, and are naturally abundant. Many alternative energy sources have already been explored and tested, even on an industrial scale, including biomass, fuel materials of vegetable or agricultural nature used for heating, electric generation and transport purposes. The aim of the paper is to introduce methods for production, transmission and use of energy in an economic, convenient, reliable and repetitive manner, without producing hazardous waste materials.

Currently, approximately $45 \%-50 \%$ of the total fuel and energy resources are used in boiler houses and other heating systems generating only heat. There are over 200000 boiler houses in Russia, of which 73000 are municipal. In boiler houses servicing heating networks, $47 \%$ of thermal energy is generated. In cities with populations of 100000-500000, the majority of consumers are provided with heat by boiler houses. Even in Moscow, $30 \%$ of thermal energy is generated by boiler houses. Energy transport potential is not completely utilized in boilers. In order to improve the existing situation it is necessary to upgrade and re-equip these boiler houses to the level of mini heat power plants where both thermal and electric power will be generated (cogeneration).

One objective in the development of electric power generation is increasing the share of distributed power generation so the energy production cost is reduced due to lower costs for energy transport from deposits to power plants and for electric power transfer from power plants to customers. 


\section{Biomass energy resources}

In Russia, over $100 \mathrm{Mt}$ of biomass available for energy purposes is produced per year. The energy equivalent of this amount of raw materials is more than $40 \mathrm{Mt}$ of reference fuel $(300000 \mathrm{GWh})$. Only $10 \%$ of this renewable biomass resource is involved in recycling processes. One of the largest producers of waste is agriculture. According to statistics, in 2010 in Russia agriculture and forestry sectors produced almost $68 \mathrm{Mt}$ of waste. Of the total amount of waste used or neutralized, $18.8 \mathrm{Mt}$ accounted for at least $28 \%$ of the waste volume.

Effective and reliable sources of raw materials for bioenergy will come from the forestry sector. Russia's forest land and forests represent $69 \%$ of the country. The wood reserves are about 82 billion cubic meters, more than a quarter of world reserves. Over 500 million cubic meters of wood is harvested annually and this figure continues to grow $^{[2-4]}$.

\section{Role of agriculture in the biofuel market}

In 2013, the author was appointed as a member of the Oversight Group to review the report of the High Level Panel of Experts on Biofuels and Food Security. This report, under the guidance and oversight of the High Level Panel of Experts Steering Committee, analyses the issues of food security related to the development of biofuel world markets. Prospects for biofuels use remain a subject of debate around the world. Research and development in this area continues to find innovative approaches that may deliver not only solutions but also reveal new, unanticipated problems. However, there is no doubt that these problems are of vital importance for large areas of the globe $^{[5]}$.

At the same time, it has to be noticed that safety and sustainability of life are not only limited by food and potable water supply. The environmental issues are also of prime importance and the substitution of fossil fuels by biofuels is believed to be one of the most effective approaches to reduce the anthropogenic impact on the nature.

The use of fluid and solid biofuels around the world grows at $10 \%$ or more per year. Most intensively the biofuel market has been developing in the EU and is expected to exceed $10 \%$ by the year 2020 in the transport sector of Europe. So it is evident that the problem has to be solved in a way that accommodates multiple factors, including social, economic, environmental and technological aspects.

Our vision for the possible solutions for biofuel production and utilization is based on the recent trends in power and transport industries. These trends are decentralized power generation and increasing growth in electric traction. Therefore, the share of fuel for internal combustion engines derived from biomass, and the consequent demand for energy crops such as rapeseed and maize, will continue to decrease.

The role of burner biofuels for decentralized power generation will grow significantly. This trend has to be viewed as an advantageous one in many aspects.

Firstly, the existing burner biofuel preparation technology is relatively simple and does not require expensive biomass components extracted from plants traditionally used for food. Biomass pretreatment cycles are also substantially simpler in the case of biofuels designed for external combustion processes. For these purposes various kinds of organic waste can be used that are commonly produced in huge amounts and constitute a great problem for their environmentally safe and economically expedient utilization.

Extensive biomass resources produced in rural areas have a powerful potential for local cogeneration sector development and independent heat and power supply, based on mini-cogeneration plants operating on composite burner biofuels, in areas with practically no access to the grid or where the grid power quality and/or reliability are poor.

Composite biofuels are principally prepared on the basis of hydrous organic components of various plants. It is well known that up to $20 \%$ of water contained in any fuel in the form of microfine emulsions acts as catalyst during combustion, making the process essentially more intensive and efficient. Thus, only $10 \%$ of water in uniform grade of heavy fuel oil results in a reduction in carbon soot of $80 \%$ $90 \%, \mathrm{NO}_{X}$ by $50 \%$ and $\mathrm{SO}_{X}$ by $30 \%{ }^{[6]}$.

\section{Main obstacles to biofuel production}

The main obstacle to developing biofuel production in Russia is a misguided state excise policy, such that the cost of the new fuel will be higher than petroleum. Biofuel production in Russia is subject to the same taxes as vodka. Support for biofuels should be by the abolition of high excise taxes on motor spirit. Unless these taxes are removed, the production of biofuels will never be profitable.

Land availability, population density and per capita income may provide preliminary orientation to the desirability of biofuel policies and the type of policy that would be most appropriate. Innovative technology can identify tradeoffs of different systems of production and their positive and negative impacts on food security. The biofuel industry has a huge potential for revival of the rural economy and at the same time will contribute to energy independence and reduced greenhouse gas emissions.

In recent years the development of the industry has slowed, as the production of biofuels from agricultural 
products has caused a global rise in food prices. It has been shown that biofuels threaten food security through price increases. Changes in the structure of land investments have resulted in displacement of traditional communities, the replacement power supply and deepening food insecurity.

Sorghum energy plantation in Russia and economic parameters of biofuel manufacture are presented in Fig. 1 and Table 1.

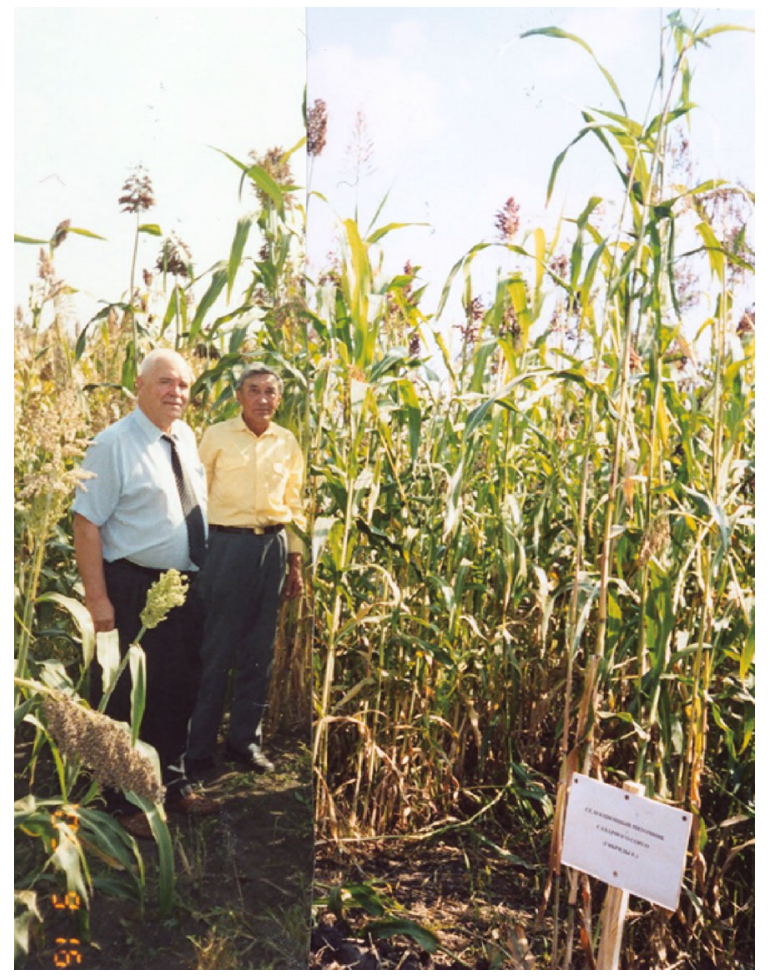

Fig. 1 Sorghum plantations in the Rostov area of a selection by the member of Russian Academy of Agricultural Sciences B.N. Malinovsky (on the right) yields $130 \mathrm{t} \cdot \mathrm{hm}^{-2}$, producing $15 \mathrm{t} \cdot \mathrm{hm}^{-2}$ biofuel.

Table 1 Economic parameters of biofuel manufacture from sorghum and wheat

\begin{tabular}{lc}
\hline Parameter & Value \\
\hline Expenses for sorghum cultivation & $100 \mathrm{USD} \cdot \mathrm{hm}^{-2}$ \\
Yield of dry biomass & $30 \mathrm{t} \cdot \mathrm{hm}^{-2}$ \\
Manufacture of biofuel & $15 \mathrm{t} \cdot \mathrm{hm}^{-2}$ \\
The production cost of biofuel & $250 \mathrm{USD} \cdot \mathrm{t}^{-1}$ \\
Sale price of biofuel & $500 \mathrm{USD} \cdot \mathrm{t}^{-1}$ \\
Annual volume of sales per hectare & $500 \mathrm{USD} \cdot \mathrm{t}^{-1}$ \\
Wheat cultivation & \\
$\quad$ Average yield & $2 \mathrm{t} \cdot \mathrm{hm}{ }^{-2}$ \\
Sale price & $300 \mathrm{USD} \cdot \mathrm{t}^{-1}$ \\
Annual volume of sales per hectare & $600 \mathrm{USD} \cdot \mathrm{t}^{-1}$ \\
\hline
\end{tabular}

Non-food crops competing for biofuel production should be evaluated in terms of their direct and indirect impact on food security as competing with food raw materials for the land, water, labor, capital and other investments. Numerous case studies on biofuels show the importance of the transition to a more comprehensive strategic approach to bioenergy. In countries with large hinterland biomass mobilization for different types of bioenergy may be the most effective strategy for the development of electricity and alternative energy, water management and the creation of local energy systems.

\section{Biofuel from algae}

One of the most promising biofuel-dedicated crops is microalgae (Fig. 2) ${ }^{[7,8]}$. The idea of producing biofuel from algae dates back to the 1970s when the world experienced a number of the oil shocks. The advantages of algae as a raw material for biofuel production are their enormously high productivity compared with terrestrial crops and the possibility to preserve arable lands for food production and other agricultural crops. Algae can be effectively cultivated in natural or artificial ponds on marginal lands, shallow lagoons and in water cooling systems of thermal power stations (TPS). In the latter case, it is technically easy to make use of rejected heat for optimizing algae productivity and to employ algae's explicit photosynthetic properties for utilization of $\mathrm{CO}_{2}$ contained in TPS flue gases.

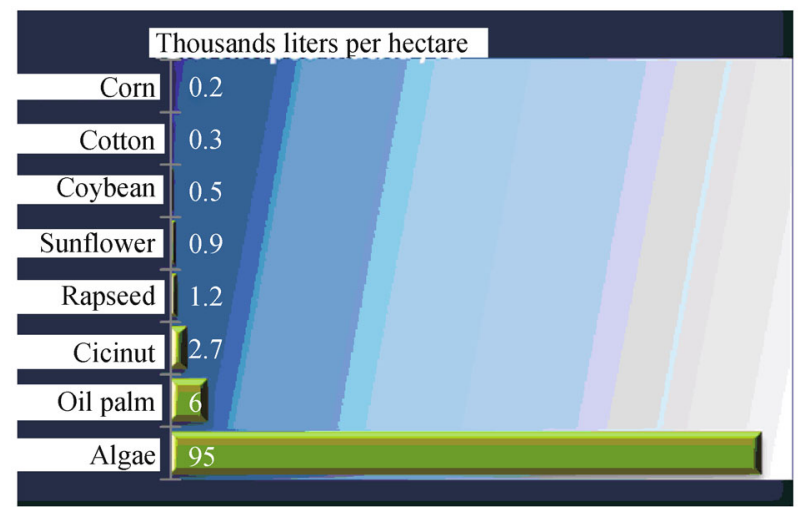

Fig. 2 Comparative data on raw oil production per hectare of area allocated for crop cultivation

Algae cultivation in closed photobioreactors is an option that makes it possible to obtain phytomass of specific chemical composition for enhancement of biofuel chemotological properties. So far, biofuel dedicated algae cultivation on a commercial scale has not been reported because the research in this field has remained focused entirely on biodiesel as the only option. The problem is that the cost of biodiesel produced from algae grown in ponds would amount to 240-332 USD per barrel (Lawrence 
Berkeley National Laboratory, 2010) while the current price of crude oil does not exceed 100 USD per barrel. This was the major reason that the US Department of Energy closed its algae research program in 1996. A decade passed before it was started again, but algae derived biodiesel has not yet found commercial application ${ }^{[8]}$.

Our research has demonstrated the possibility of overcoming the algae fuels production cost barrier within the concept of composite biofuels described above. As a hydrous component of composite burner biofuel, microalgae suspension is an ideal organic material featuring very high grade natural dispersiveness (down to $1 \mu \mathrm{m}$ for planktonic strains derived from Chlorella vulgaris, the most common species in natural ponds in temperate climates). Microalgae suspension can be blended easily into heavy grade fuel oil using cavitation technology without any pretreatment insuring ultrafine and stable biofuel $^{[7,8]}$.

There is a great opportunity for microalgae to be used as alternative raw materials for biodiesel production. Further progress depends on finding fast-growing and resistant microalgae strains with high oil content and algology development using the complete range of biotechnological, genome and biochemical methods, and on improvement of cultivation process using benefits of open methods of growing large amounts of biomass and photo bioreactor cultivation of strains with specified technological properties. This is possible through a combination of open and photo bioreactor cultivation (Fig. 3, Fig. 4) ${ }^{[7,8]}$.

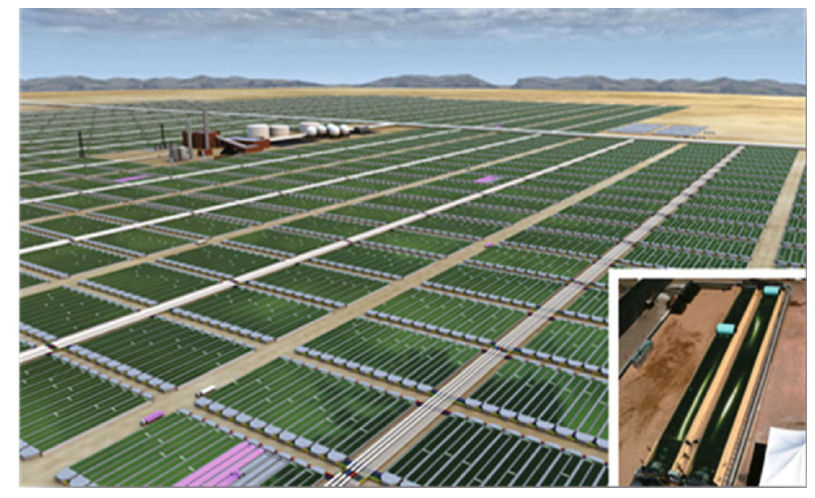

Fig. 3 Industrial cultivation of microalgae in open ponds ${ }^{[8]}$

A new trend is to use algae to remove $\mathrm{CO}_{2}$ from the exhaust gas from TPS and other industries. The exhaust gases contain a high percentage of $\mathrm{CO}_{2}$ (up to 20\%). Typical thermal power generation using coal emits up to $13 \% \mathrm{CO}_{2}$. Thus, the thermal power plants are a major source of $\mathrm{CO}_{2}$ air pollution. Exhaust emission of $\mathrm{CO}_{2}$ and use of alternative energy will lead to stabilization of atmospheric $\mathrm{CO}_{2}$ and prevent global warming. Microalgae absorb $\mathrm{CO}_{2}$ during growth, so that they can be used to remove $\mathrm{CO}_{2}$ from the exhaust gas of thermal power plants and other industries.

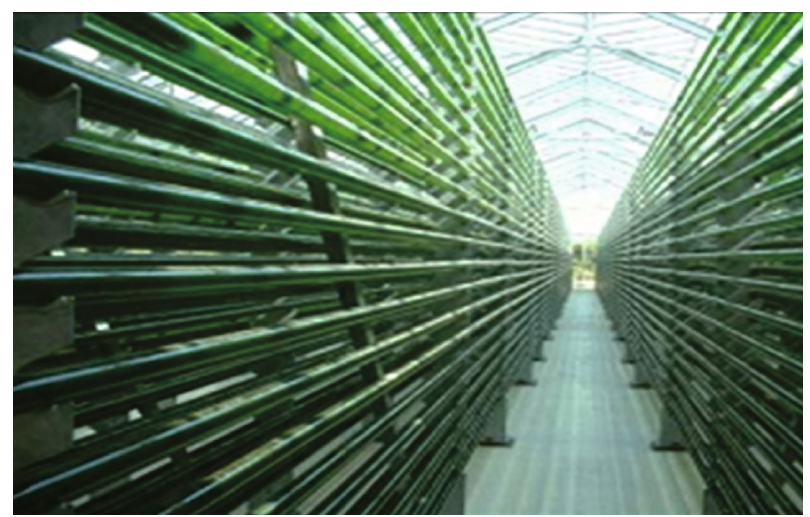

Fig. 4 Cultivation of microalgae in photo bioreactors ${ }^{[8]}$

Currently microalgae is mostly grown on a commercial scale in artificial shallow ponds of up to thousands of square meters. Problems of cultivation of microalgae in ponds led to the development of new technology for growing, based on the use of photobioreactors for algae for the optimal functioning of the cultivation (or biofuel from microalgae).

Photobioreactors for growing algae can occupy $10 \%$ $20 \%$ of the land used in open ponds for the production of the same amount of algae. To use photobioreactors commercially, they need to have the most efficient use of solar energy, and the necessary conditions of cultivation to maintain the purity of the microalgae cultures.

\section{Plasma processing of solid organic waste}

The Russian scientists have developed ecologically-clean innovation technologies for processing solid organic waste of cities and agricultural enterprises into electrical energy and heat at plants with $100 \mathrm{t}$ per day capacity with cogeneration of $1 \mathrm{MW}$ of electric and thermal power ${ }^{[1,9]}$. Waste is processed at high capacity in sealed reactors and not combusted as in plants from other countries. The application of such technologies will make it possible to considerably improve ecological sustainability and reduce energy intensiveness of the processes. The total volume of waste dumped at landfills in RF cities amounts to 95000 $\mathrm{Mt}$ and is annually increased by $3500 \mathrm{Mt}$. The total area of solid waste landfills in the RF is $2500 \mathrm{~km}^{2}$.

Advances in the RF provide gas reciprocating units with 1.3 MW electric and heat capacity as cogeneration power plants, using plasma technologies, to achieve rapid pyrolysis with a capacity of $100 \mathrm{t}$ of solid organic waste per day and internal electricity consumption of $300 \mathrm{~kW}$ for gas fuel production from cogeneration power plants operation. These internal energy consuming cogeneration power plants will generate $1 \mathrm{MW}$ of electric capacity into energy and process $36000 \mathrm{t}$ of solid organic waste per year. The RF is considering distributed cogeneration that does 
not require construction of main power transmission lines, as well as fuel extraction and transportation. In estimating payback periods of the energy projects being considered, it is necessary to take into consideration the economic effect from elimination of landfills, land re-cultivation and environmental improvement of cities and rural settlements.

Other solid organic waste resources include forestry and agricultural residues, and in woodless areas - energy plantations of fast-growing trees on land not suitable for agricultural production, for example, in areas around the nuclear power stations in Chernobyl and Fukushima, and deserts, marshy and saline lands.

In the fast pyrolysis method, a substantially higher decomposition rate and energy saving is obtained owing to rapid $\left(10^{4}{ }^{\circ} \mathrm{C} \cdot \mathrm{s}^{-1}\right)$ heating of organic compounds (thermal shock). Under thermal shock conditions molecules of the processed materials have no time for energy exchange. That is why nearly all input energy is spent on their chemical decomposition. The specific heat of combustion for the liquid phase intended as the base fuel component for internal combustion engines was estimated as $23.027 \pm 2.093 \mathrm{MJ} \cdot \mathrm{g}^{-1}$. An experimental demonstration model of the plant has been designed and manufactured. This technique has an important social objective: providing consumers with local reliable power supply insuring independence and ecological safety ${ }^{[9,10]}$.

A pilot production plant has been designed and manufactured for decomposition of any type of solid combustible feedstock (e.g., coal, peat, biomass and vegetable wastes) into mainly gaseous and liquid fractions (Fig. 5). An efficient decomposition method has been developed and the block diagram of the industrial plant for manufacturing of liquid internal combustion engine fuel components has been described. Fast pyrolysis related technological solutions have patents pending at VIESH, Russia.

\section{Plasma processing of liquid organic wastes}

Key sources of environmental pollution that can also be used as renewable fuel resources for cogeneration power plants include liquid sewage effluents of cities and settlements, liquid effluents from pig farms, liquid waste from sugar refineries and distilling plants.

To process liquid organic waste with $80 \%-95 \%$ water content into electric energy, pyrolysis technologies are not suitable because of high energy costs of the process of preliminary drying liquid organic waste. Russian scientists have developed new technologies for liquid organic waste processing based on supercritical water oxidation of organic substances into liquids. For a cogeneration power plant with $1 \mathrm{MW}$ capacity, processing of $150 \mathrm{t}$ of

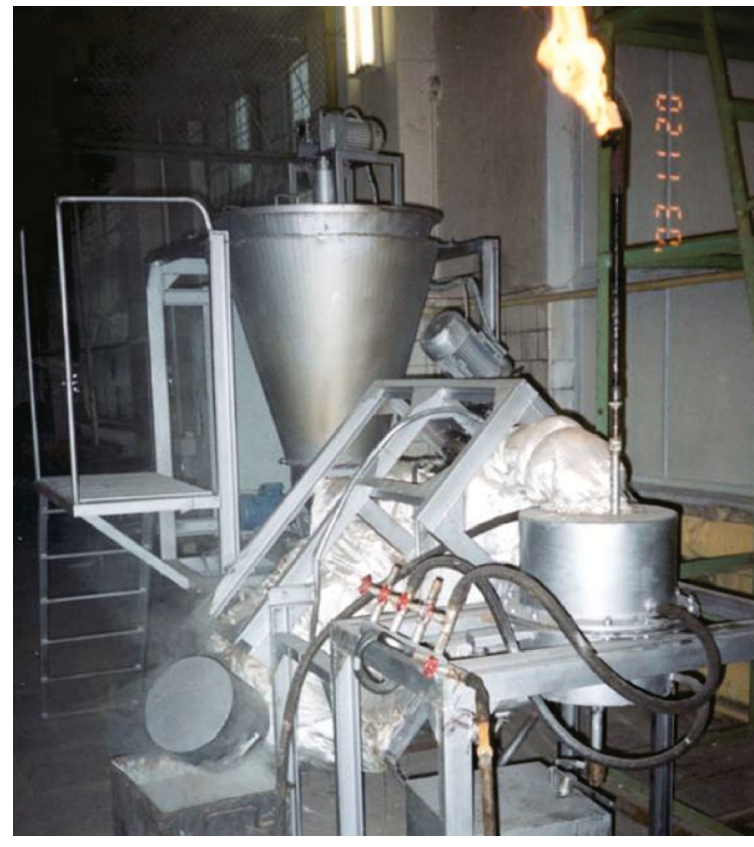

Fig. 5 Equipment for testing fast pyrolysis at VIESH

liquid organic waste per day is required because of lower organic content in liquid organic waste in comparison with solid organic waste. For cities this allows a reduction in areas occupied by waste treatment facilities and to eliminate sewage disposal into the sea, as in Sochi, Gelendzhik, Malaga, Barcelona (Spain), in towns on the sea in Australia and other countries.

Large-scale pig farms keeping several sediment ponds for dung effluents, will be able to provide electricity and heat, not only for their own needs, but also for villages and rural areas situated nearby ${ }^{[1,9]}$.

\section{Microwave assisted combustion}

In the Laboratory of Biofuel Technologies of VIESH, experiments are conducted on microwave assisted combustion of composite biofuels comprising $50 \%$, or even more, of liquid and/or solid organic components of various natures, using flame cups of unique design. Composite burner biofuel typically contains $20 \%-50 \%$ of hydrous organics (e.g., plant biomass and cattle dung) blended in a heavy, low grade, oil derivative such as fuel oil using energy efficient technological methods that employ hydrodynamic and ultrasonic cavitation processes to obtain a stable microfine multi-component emulsions/ suspension (Fig. 6).

This approach makes it possible to implement the environmental advantages of biofuels at substantially lower production cost without the need for additional large areas arable land ${ }^{[1,9]}$. 
(a)

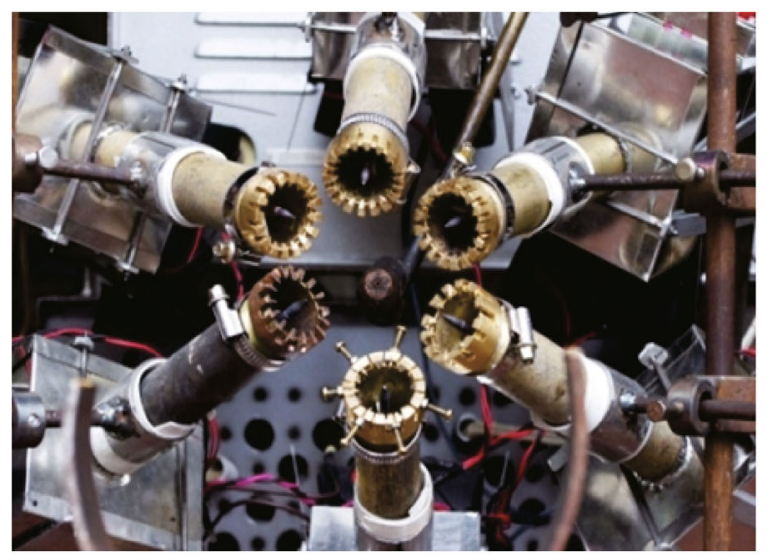

(b)

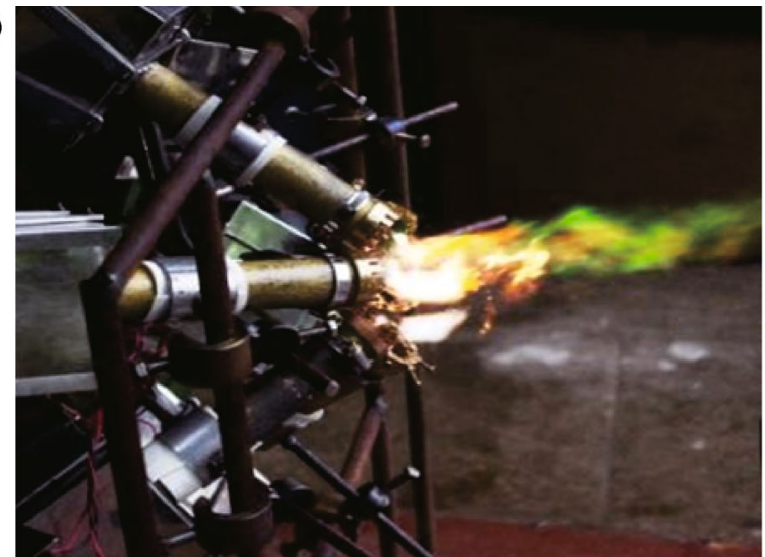

Fig. 6 Plasma conversion of liquid organic wastes. (a) Electric plasma generator; (b) burning of liquid organic wastes.

\section{Low-carbon multicomponent fuel}

Another approach to the reduction of costs for motor and stove fuel is the production of composite multicomponent fuel. Hydrocarbon fuel content (diesel fuel or mazut) amounts to $80 \%$ of multicomponent diesel fuel. The working model of equipment for multicomponent fuel production with $2 \mathrm{t} \cdot \mathrm{h}^{-1}$ capacity is installed at the biofuel laboratory at VIESH (Fig. 7) ${ }^{[1,9]}$. Comparison of charac-

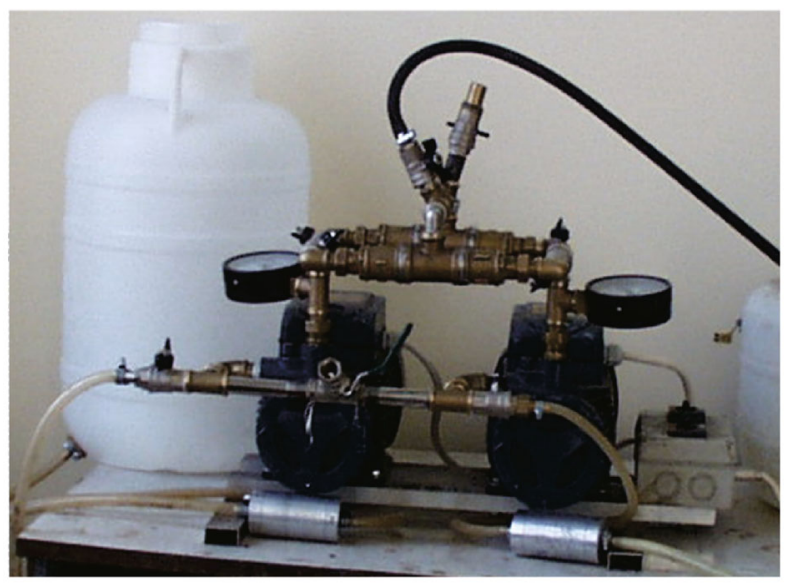

Fig. 7 Equipment for multicomponent fuel production with $2 \mathrm{t} \cdot \mathrm{h}^{-1}$ capacity at the Bioenergy Department of VIESH teristics of diesel, mazut and multicomponent motor fuel are presented in Table 2 and Table 3.

The use of multicomponent fuel in tractors, ships, automobiles, locomotives and stationary diesel engines leads to a reduction of harmful emissions into the atmosphere by $30 \%-40 \%$. In stove multicomponent fuel carbon fuel content is $50 \%-60 \%$ which halves heating costs.

\section{Non-carbon silicon fuel for energy generation}

By analogy with hydrocarbon energy this trend can be termed silicon energetics. Let us consider four known methods of using silicon for energy generation ${ }^{[11]}$ :

1. Silicon combustion in air:

$$
\mathrm{Si}+\mathrm{O}_{2}=\mathrm{SiO}_{2}
$$

2. Silicon catalytic combustion in water:

$$
\begin{gathered}
\mathrm{Si}+2 \mathrm{H}_{2} \mathrm{O}=\mathrm{SiO}_{2}+2 \mathrm{H}_{2} \\
2 \mathrm{H}_{2}+\mathrm{O}_{2}=2 \mathrm{H}_{2} \mathrm{O}
\end{gathered}
$$

3. Silicon catalytic combustion in nitrogen:

Table 2 Comparison of the characteristics of diesel, and multicomponent motor fuel

\begin{tabular}{lccc}
\hline No. & Fuel charateristics & Summer diesel fuel & Munticompotent motor fuel with $80 \%$ diesel content \\
\hline 1 & Lowest combustion value $/\left(\mathrm{kJ} \cdot \mathrm{kg}^{-1}\right)$ & 42776 & 44327 \\
2 & Mass fraction of sulfur $/ \%$ & 0.130 & 0.038 \\
3 & Kinematic coefficient of viscosity at $20^{\circ} \mathrm{C} / \mathrm{cSt}$ & 4.8 & 3.9 \\
4 & Flash temperature in a closed cup $/{ }^{\circ} \mathrm{C}$ & 75 & 73 \\
5 & Cetane number & 50 & 61 (Standard Euro-4) \\
6 & Industrial purity class & 12 & Over 17 \\
7 & Fuel storage time per year & - & 1 \\
\hline
\end{tabular}


Table 3 Comparison of characteristics of mazut and multicomponent motor fuel

\begin{tabular}{lccc}
\hline No. & Fuel charateristics & High-sulfur mazut & Munticompotent fuel with $80 \%$ mazut content \\
\hline 1 & Loweset combustion value $/\left(\mathrm{kJ} \cdot \mathrm{kg}^{-1}\right)$ & 41816 & 44101 \\
2 & Mass fraction of sulfur $/ \%$ & 1.71 & 0.87 \\
3 & Kinematic coefficient of viscosity at $20^{\circ} \mathrm{C} / \mathrm{cSt}$ & 7.3 & 5.9 \\
4 & Flash temperature in a closed cup $/{ }^{\circ} \mathrm{C}$ & 93 & 97 \\
5 & Fuel storage time per year & - & 1 \\
\hline
\end{tabular}

$$
\mathrm{Si}+2 \mathrm{~N}_{2}=\mathrm{SiN}_{4}
$$

4. Physicochemical reactions in molten sodium silicate:

$$
s \mathrm{Na}_{2 r} \mathrm{SiO}_{(2 r+s)} \Rightarrow \mathrm{Na}^{+}+\mathrm{Si}_{m} \mathrm{O}_{n}
$$

Comparison of calorific efficiency of silicon and hydrocarbons is given in Table 4.

Initial and final products of silicon energetics are not radioactive, do not pollute the environment and do not generate greenhouse gases. In combustion in air, silicon as a fuel is twice as effective as coal and is almost equal to natural gas. If associated with nitrogen in oxygen-free energetics, silicon as fuel is twice as effective as coal. Nitrogen content in the atmosphere greatly exceeds all other gases. Thermal energy of high-temperature physicalchemical reactions in heterogeneous media of highmodulus silicate solutions, for example sodium silicate exceeds the calorific value of hydrogen fuel with the same mass by a thousand times. Electrochemical current source with molten electrolyte with nonstoichiometric composition on the basis of sodium silicate with megawatt capacity has calculated price of electricity of $80 \mathrm{EUR} \cdot \mathrm{MWh}^{-1}$.

Another promising non-carbon fuel is nanometric particle nickel powder producing huge amounts of thermal energy as the result of cold fusion with hydrogen ${ }^{[12]}$ :

Alternative non-carbon source of thermal energy

Temperature $150-500^{\circ} \mathrm{C}$
Pressure $2 \times 10^{5}-2 \times 10^{6} \mathrm{~Pa}$

$\downarrow \downarrow$

One gram of nanometric particle nickel powder

+ Hydrogen $\Rightarrow$ Copper +517 t of oil equivalents

\section{Biofuels for transport industries}

A vision of the possible solution in the sphere of biofuels production and utilization is based on the recent trends in power and transport industries.

A transport system without engine and chemical battery is under development. Resonant single-conductor electric power transmission systems (Fig. 8, Fig. 9) ${ }^{[13]}$ would offer global opportunities for developing non-contact highfrequency electric transport. The well-known non-contact method for transmitting electric power to a vehicle through an air-core transformer (using the electromagnetic induction method and conventional single-phase power transmission lines) has basic limitations on the transmitted power level, the transmission efficiency and the line length; therefore, it is not currently used.

Experimental models of non-contact electric vehicle and tractor are presented in Fig. 10.

It is possible to imagine that in the future large, green cities, full of flowers, without exhaust gases and smog. A

Table 4 Comparison of calorific efficiency of silicon and hydrocarbons

\begin{tabular}{lcc}
\hline Reaction number & Fuel & Calorific efficiency \\
\hline 1 & Silicon & $858.294 \mathrm{~kJ} \cdot \mathrm{mol}^{-1}$ \\
2 & Silicon & $858.294 \mathrm{~kJ} \cdot \mathrm{mol}^{-1}$ \\
$2 \div 3$ & Silicon & $1.144 \mathrm{MJ} \cdot \mathrm{mol}^{-1}$ \\
4 & Silicon & $753.624 \mathrm{~kJ} \cdot \mathrm{mol}^{-1}$ \\
- & Methane & $879.228 \mathrm{~kJ} \cdot \mathrm{mol}^{-1}$ \\
- & Coal & $393.559 \mathrm{~kJ} \cdot \mathrm{mol}^{-1}$ \\
3 & Hydrogen & $285.958 \mathrm{~kJ} \cdot \mathrm{mol}^{-1}$ \\
5 & Sodium silicate & $35.587 \mathrm{GJ} \cdot \mathrm{mol}^{-1}$ \\
- & Heavy oil & $35.587 \mathrm{MJ} \cdot \mathrm{mol}^{-1}$ \\
\hline
\end{tabular}




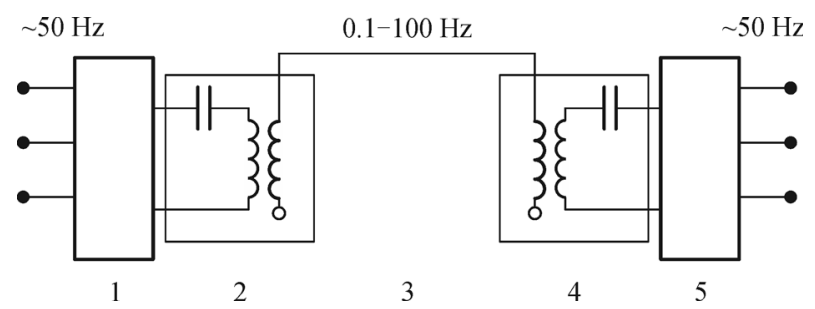

Fig. 8 Resonant system for electric power transmission. 1 - converter; 2, 4 - resonant high-frequency Tesla transformers; 3 - singleconductor high-voltage line connecting the transformers; 5 - inverter.

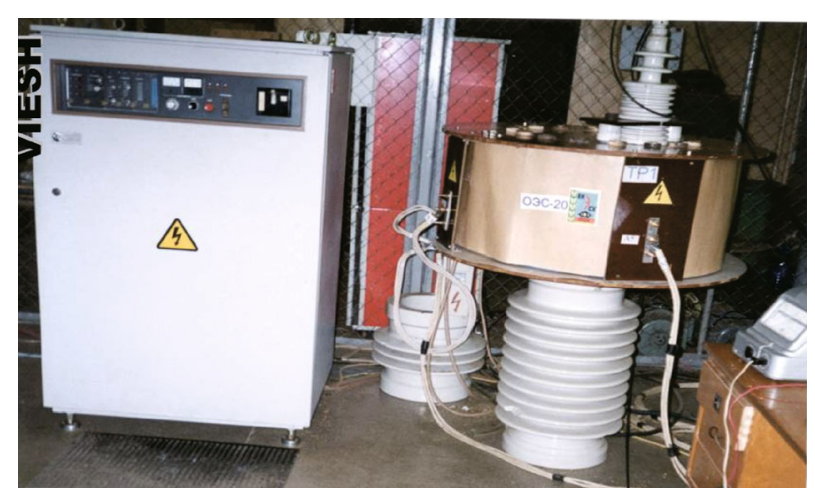

Fig. $920 \mathrm{~kW}, 5 \mathrm{kHz}$ resonant electric power transmission system

cable transmission line will be laid in this city under each driving lane along main roads, and each vehicle has an electric motor and a non-contact trolley in addition to the combustion engine. The traffic along major highways between cities can be organized in the same way, including possible use of automated vehicles controlled by robots and computers.

The use of an electric non-contact drive in the agricultural industry opens the prospects for substantial fuel saving and developing robots controlled by computers with satellite navigation, intended for tillage, cultivation and harvesting agricultural products. In this case the agricultural plants will be transformed into field factories organized according to the principles of automated industrial enterprises. Thus, three present-day electrification problems can be solved: energy saving, reducing harmful gas emission and automation of agricultural production process.

\section{Agriculture for the Arctic zone}

The most efficient way of solving the problem of Russia's food security is based on techniques aimed at the settingup of fractal innovative biotechnological cluster platforms, intended for the accomplishment of different-scale projects for the production of organo-functional food and formation of a network of different scale automated production complexes. The technological and economic advantages of the new approach to the solution of the problem of food safety in Russia, primarily the problems of food supply to the regions of Siberia, the Far East and the Arctic zone, have been considered. Advanced biotechnologies leading to accelerated growing of agricultural plants with the use of synergoponics, new technological equipment for industrial production of organo-functional food, as well as innovative methods of quality control and safety of produced goods on the basis of biotesting, have been developed and implemented ${ }^{[14]}$. (a)

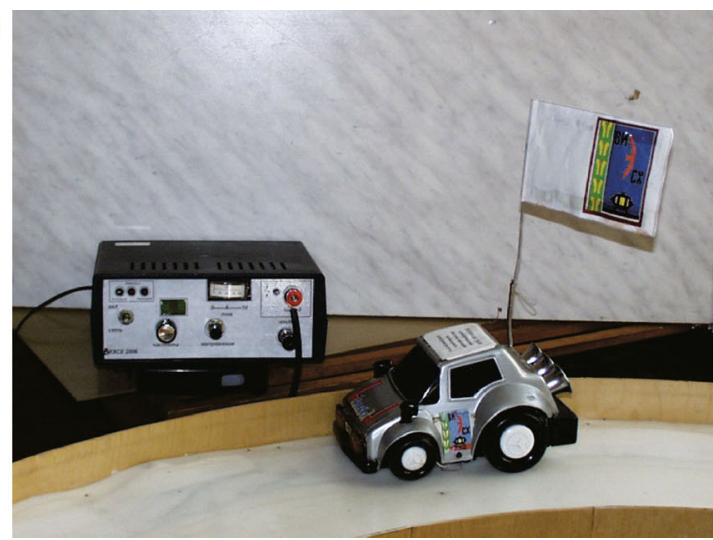

(b)

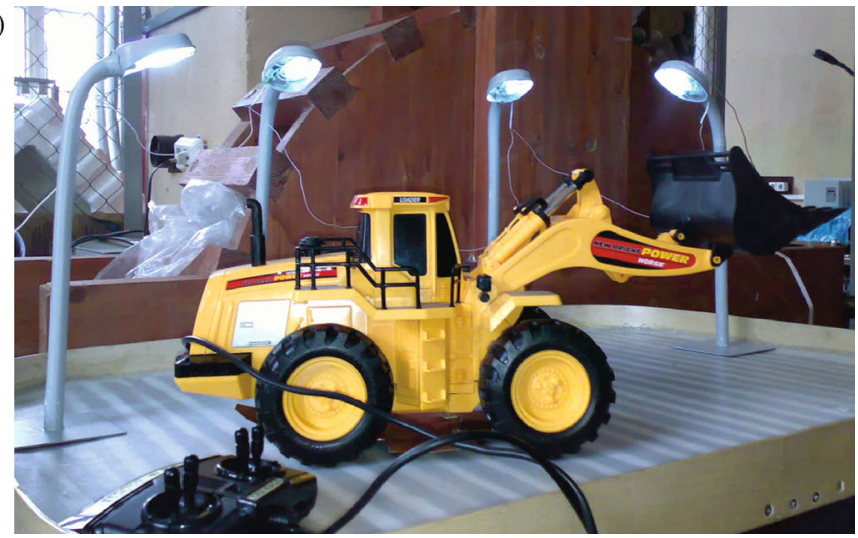

Fig. 10 Experimental models. (a) Non-contact high frequency electric vehicle; (b) a model of an electric tractor, using non-contact trolley. 


\section{Fuel-free energy generation}

Each technological mode and corresponding energy source is characterized by the phases of development, in turn flourishing and then declining. The Twentieth Century was the period of maximum development and use of hydrocarbon energy which by the end of the Twenty-First Century may be replaced by fuel-free power generation on the basis of renewable energy sources. The decline in the development of hydrocarbon energy will stem not from depletion of hydrocarbons reserves but from the development of new energy technologies and emergence of new energy transporters allowing reduced costs of energy resources, raised energy use efficiency and diminished negative impacts on environment ${ }^{[11]}$.

Currently the fuel energy generating industry provides $87.1 \%$ of the energy consumed worldwide. Local and foreign experts estimate that by the end of this century over $80 \%$ of the global energy consumption will be provided by non-fuel energy technologies: hydrological, biologic, solar, wind and geothermal energy plants alongside hydrogen energy. The advanced Russian technologies for solar energy, include chlorine-free technologies for solargrade silicon production, the technologies for silicon solar modules with $20 \%$ efficiency at 60 -fold concentration of solar radiation, the technologies of assembling solar modules with $40-50$ years' service life and the technologies for concentrator solar modules ${ }^{[1,11]}$.

The energy model of the future world offered by VIESH in 2004 is based on round-the-clock electric power generation by solar power plants and on energy systems and networks on the basis of Nikola Tesla technologies ${ }^{[11,13]}$. In Russia, new energy technologies have been developed allowing the creation of a global solar energy system within the framework of an international project involving energy companies concerned, the International Energy Foundation, IRENA, UNESCO, the UN and other national and international organizations and financial institutions. The development of solar energetics silicon will make it possible to reduce the negative impact of hydrocarbon energy on climate, environment and human health, as well as to reduce greenhouse gases emission down to a safe level.

Such a global solar energy system would need to generate electrical power of $20000 \mathrm{TWh}$ per year which would be equivalent to current global energy consumption. The global solar energy system (Fig. 11) comprises three solar power plants (SPP) installed in deserts of Australia, Africa and Latin America and connected to one another and to national energy systems of all the countries all over the world with waveguide resonant lines for electric power transmission on the basis of Nikola Tesla technologies.

Parameters of each solar power plant ${ }^{[11]}$ :

- Size $200 \times 200 \mathrm{~km}^{2}$;

- Electric capacity $2.5 \mathrm{TW}$;

- Efficiency 25\%;

- Service life 50 years.

Computer simulation of the global power system parameters with due account taken of meteorological data on solar radiation for the whole observation period at proposed SPP location confirmed uniform year-round electricity production irrespective of season, equivalent to

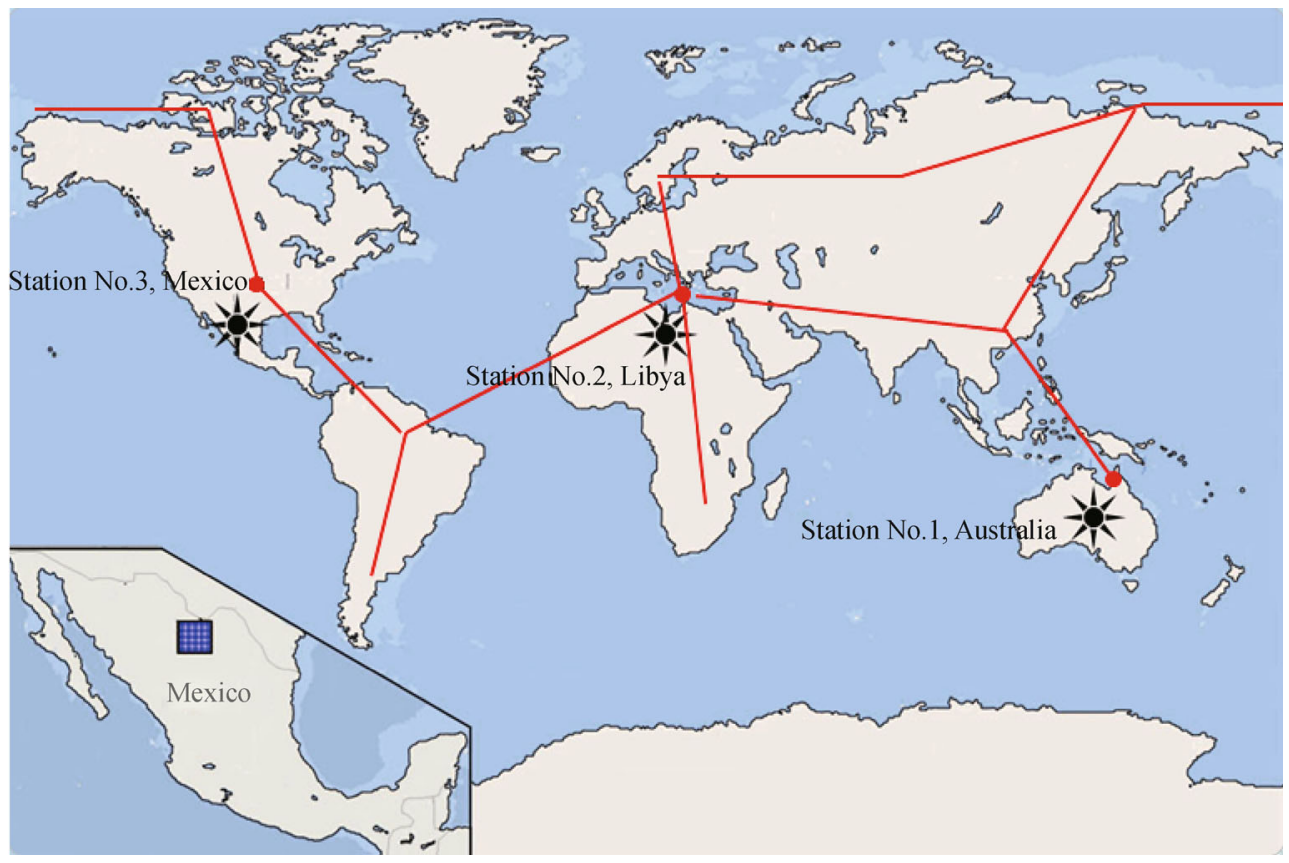

Fig. 11 Mega project global solar power system 
the amount of global consumption ${ }^{[11]}$.

Modern solar energy is mainly based on planar lowvoltage silicon solar modules without concentrators with $15 \%$ efficiency and overall production of modules generating $30 \mathrm{GW}$ per year with the rate of production of silicon for solar panels of around $200 \mathrm{kt}$ per year. Silicon content in the Earth core exceeds the content of all other elements with the exception of oxygen, which is why it is silicon that will remain the basic material for solar energy in future. SPP with $2.5 \mathrm{TW}$ capacity at 100 concentration would require $300 \mathrm{kt}$ of silicon which is comparable to current volume of silicon production for electronics and photovoltaics. A stationary PV concentrator module installed at a VIESH test site is shown in Fig. 12.

SPP with cylindrical concentrators and a photoreceiver on the basis of a high voltage solar module (HVSM) with $20 \%$ efficiency and 50-60 concentration is under development. The area of photoreceivers with HVSM with concentrators will be reduced 50-60 times. High voltage solar module has operating voltage $1000 \mathrm{~V}$ and the size $0.70 \mathrm{~m} \times 0.07 \mathrm{~m}\left(20000 \mathrm{~V} \cdot \mathrm{m}^{-2}\right)$ (Fig. 13).

A solar power plant consisting of solar modules without concentrators with an estimated $40-50$ years' service life (GNU VIESH technology patent) and capable of generat-

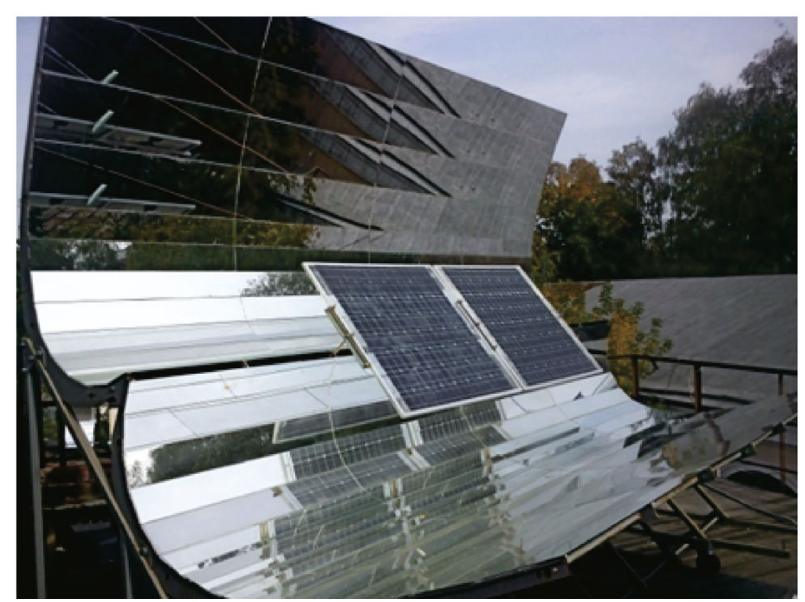

Fig. 12 Experimental model of a non-tracking solar concentrator module with $800 \mathrm{~W}$ peak capacity. The photoreceiver area is reduced by a factor of three in comparison with solar power plants without concentrators.

ing $1150 \mathrm{~W}$ peak capacity installed at the GNU VIESH testing site is shown in Fig. 14.

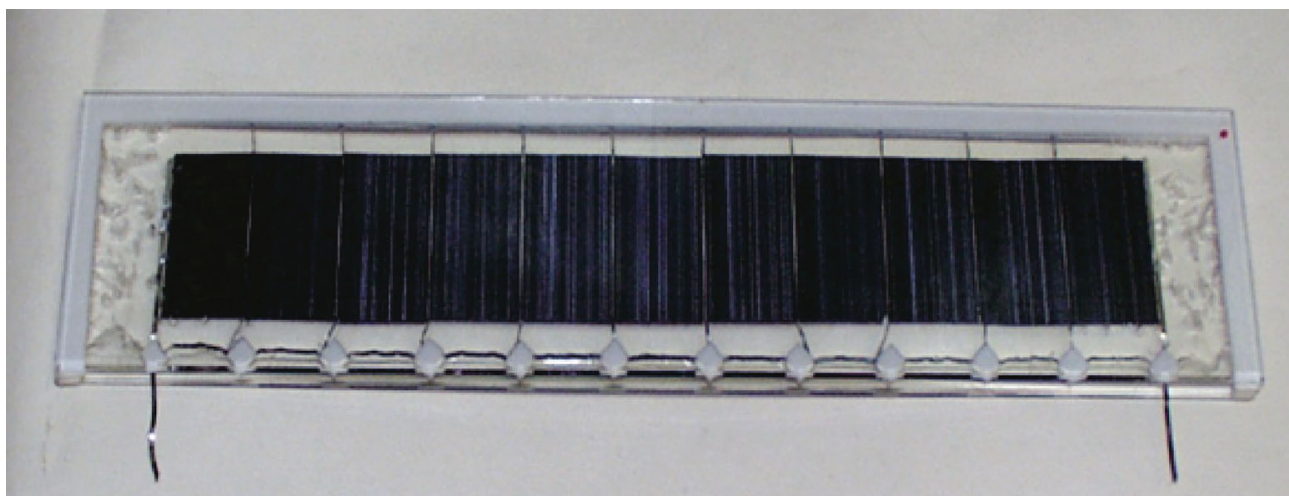

Fig. 13 High voltage PV module

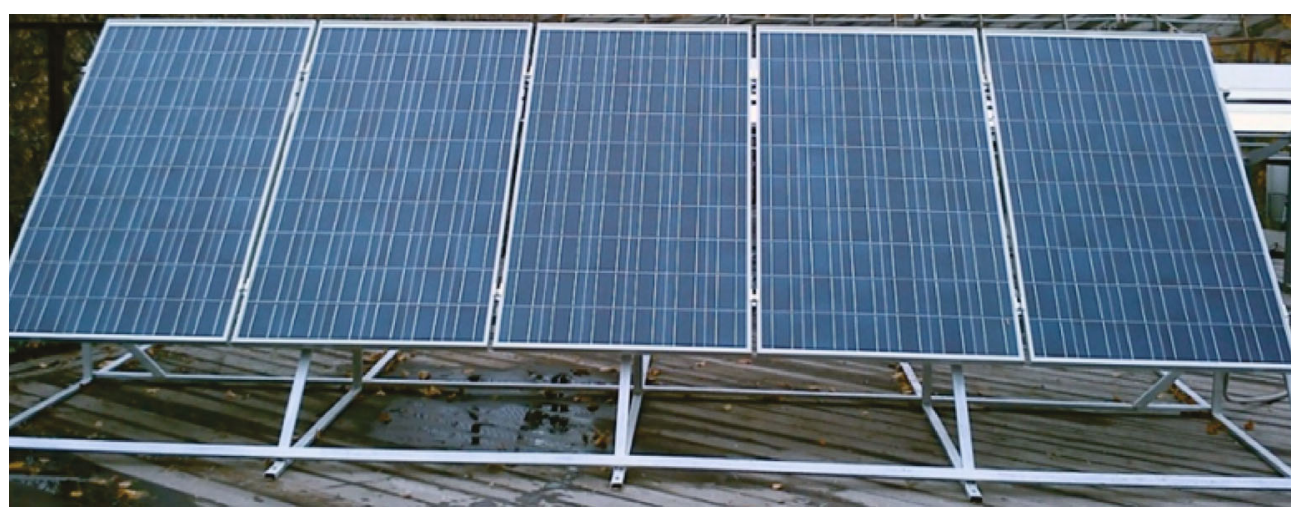

Fig. 14 Solar power plant with $1150 \mathrm{~W}$ capacity and with 40-50 years of service life 


\section{Conclusions}

(1) The current situation in the field of fuel and energy is characterized by unstable prices for fossil fuels and ever growing technogenic pressure on environment. These factors determine the main political, economic, legislative and technological trends. In the scientific and technological sphere this stimulates the search for new possibilities for biofuels production, notably, the use of bioresources that do not unbalance the structure of agricultural production traditionally oriented toward meeting the demand for food products. In recent years, due to the considerable increase in the use of biomass for energy purposes, serious problems have emerged related to deforestation and transfer of considerable parts of agricultural products from the food and forage industries to the energy production area. Also, the intensive wood procurement for biodiesel production leads to failure of ecosystems.

(2) The rate of biomass generated by algae exceeds many times the most productive land plants and, moreover, algae produce more useful products per unit area. Biofuels made of algae oil are termed third generation biofuels. The problem of using algae oil for energy purposes has two principal aspects determining the scale of use and applications: the search for species of oil-containing algae most suitable for cultivation, and development of optimal cultivation technology. In recent years the idea of a two-phase technology for microalgae cultivation for biodiesel production, combining closed (photo bioreactor) and open (basins and ponds) methods of cultivation has been developed. In this case closed photo bioreactors can be effectively and economically used for production of high-quality inoculum-cell suspension used as feedstock for cell culture cultivation with further introduction to nursery ponds for open cultivation. It can be concluded that at the present stage of the world economic and technological development there are great opportunities for microalgae use as alternative vegetable raw materials for biodiesel production.

(3) An innovative approach to the reduction of costs for motor and stove fuel is the production of composite multicomponent fuel with diesel oil content $80 \%$ for motor fuel and $64 \%$ for in stove fuel. Plasma technologies for solid domestic waste processing into electric energy and the technologies for liquid organic waste processing based on supercritical water oxidation of organic substances into liquids for thermal and power plants with $1 \mathrm{MW}$ capacity are under development.

(4) Comparison of parameters of a classical electric power supply system with an electric power supply system using single-wire wave-guide lines with high frequency, proposed by N. Tesla 100 years ago show that in such characteristics as current density and line losses, energy transmission distance, transmission capacity, the possibi- lity of cable and wireless power transmission the Tesla electrical systems exceeds the classical energy supply systems. In future electrified mobile robots with external wireless power supply will make it possible to organize agricultural production on the principles of "Industrial Factories on Fields" with full automation of technological processes.

(5) The energy model of the future world based on direct solar energy conversion and transcontinental terawatt power transmission with the use of resonant wave-guide technology, development by N. Tesla, is proposed. The advanced Russian technologies for solar energy include chlorine-free technologies for solar-grade silicon production, technologies for silicon high voltage solar modules with $20 \%$ efficiency at 60 -fold concentration of solar radiation, technologies for assembling solar modules with $40-50$ years' service life, and concentrator solar modules and non-carbon fuel technologies.

Compliance with ethics guidelines Dmitry S. Strebkov declare that there is no conflict of interest or financial conflicts to disclose.

This article is a review and does not contain any studies with human or animal subjects performed by the author.

\section{References}

1. Strebkov D S. The problems of increasing the energy conversion efficiency. Moscow: VIESH, 2014, 2(1): 2-9

2. Strebkov D S. Biomass energy utilization/Renewable energy. Moscow: Inter solar center, 1998, 3: 9-12

3. Strebkov D S, Besrukih P P, Tyuchov I I. Biomass energy conversion in Russia /World Renewable Energy Congress. Energy Efficiency, Policy and the Environment, 1998: 2012-2015

4. Strebkov D S, Chirkov V G. Perspectives of Russian bio-ruels export to the European Union /EuroSun 2004. Freiburg Germany: PSE GmbH, 2004, 2: 431-436

5. Strebkov D S. Biomass energy conversion/Research in agricultural electric engineering. Moscow: VIESH, 2013, 4(4): 122-128

6. Strebkov D S, Ross M Y, Egorov Y M, Filkov M N, Schekochichin Y M. Main directions of biotechnological development of renewable energy for production of alternative fuel. GNU VIESH, 2012, 2 (7): 43-53

7. Strebkov D S, Ross M Y. Biodiesel from algae. GNU VIESH, 2008: 252

8. Ross M Y. Renewable energy solutions for energy supply to consumers in Russia. Energy Bulletin, 2010, 1(8): 47-61

9. Strebkov D S. Utilization of biomass and agricultural wastes for biofuel production. Alternative Kilowatt, 2008, 4: 18-23

10. Strebkov D S. Fast pyrolysis systems technique for gaseous and liquid fuel production. In: 10th Technology Summit and Technology Platform, 2004: 1

11. Strebkov D S. On the energy model of the future world on the basis of solar silicon energetics. Moscow: VIESH, 2013, 3(3): 86-88 
12. Tsyganov E N. Cold nuclear fusion. Nuclear Physics, 2012,75(2): 174-180 (in Russian)

13. Strebkov D S, Necrasov A I. Resonant methods of electric power transmission and application. GNU VIESH, 2013: 1-584

14. Strebkov D S, Poverin D I. Research in agricultural electric engineering. Moscow: VIESH, 2014, 2(1): 10-17 